\title{
Reduced T-cadherin expression and promoter methylation are associated with the development and progression of hepatocellular carcinoma
}

\author{
QUN YAN $^{1 *}$, ZHI-FA ZHANG ${ }^{1 *}$, XIAO-PING CHEN ${ }^{1}$, DAVID H. GUTMANN ${ }^{3}$, \\ $\mathrm{MIN} \mathrm{XIONG}^{2}$, ZHEN-YU XIAO ${ }^{1}$ and ZHI-YONG HUANG ${ }^{1}$
}

\begin{abstract}
${ }^{1}$ Research Laboratory and Hepatic Surgical Center, Department of Surgery, Tongji Hospital, and ${ }^{2}$ Department of Surgery, Union Hospital, Tongji Medical College, Huazhong Universty of Science and Technology, Wuhan 430030, P.R. China; ${ }^{3}$ Department of Neurology, Washington University School of Medicine, 660 S. Euclid Ave, St. Louis, MO 63110, USA
\end{abstract}

Received November 23, 2007; Accepted January 15, 2008

\begin{abstract}
Loss of T-cadherin expression has been reported in a number of human cancers. We previously reported that T-cadherin re-expression suppressed cell growth and motility in glioma. Here, we report that the T-cadherin expression was significantly decreased in human hepatocellular carcinoma (HCC) compared to adjacent normal liver. In addition, T-cadherin expression in $\mathrm{HCC}$ with metastasis was significantly lower than in HCC without metastasis. To determine the mechanism underlying the reduced T-cadherin expression in HCC, we examined T-cadherin promoter methylation. We found that methylation of the T-cadherin promoter was present in $40 \%$ of $\mathrm{HCC}$, but absent in all adjacent liver tissues. In the HCC with T-cadherin promoter methylation, the T-cadherin expression was significantly decreased compared to HCC without methylation. To provide a functional link between T-cadherin promoter methylation and T-cadherin growth regulation, we used the HepG2 hepatoma cell line that exhibits T-cadherin promoter methylation. Treatment of HepG2 cells with the demethylating agent 5-aza2-deoxycytidine resulted in increased T-cadherin expression and reduced cell proliferation. These results demonstrate that the T-cadherin down-regulation by promoter methylation is associated with the development and progression of HCC, and suggest that T-cadherin is an important tumor suppressor in liver cancer.
\end{abstract}

Correspondence to: Professor Zhi-Yong Huang, Department of Surgery, Tongji Hospital, Tongji Medical College, Huazhong Universty of Science and Technology, 1095 Jie Fang Da Dao, Wuhan 430030, P.R. China

E-mail: zyh168@hotmail.com

${ }^{*}$ Contributed equally

Key words: T-cadherin, hepatocellular carcinoma, methylation, expression

\section{Introduction}

Hepatocellular carcinoma $\mathrm{HCC}$ following hepatitis B and C is a common malignant disease in Asia and Africa. HCC has become the second most prevalent cause of cancer-related deaths in mainland China, with about 137,500 deaths per year (1). Although hepatic resection remains the most effective treatment $(2,3)$, the high rate of postoperative recurrence and tumor metastasis inevitably leads to poor clinical outcome. To develop potential effective treatments for $\mathrm{HCC}$, recent studies have focused on understanding the molecular pathogenesis of HCC formation and progression. HCC is closely linked to persistent HBV infection and the intake of $\alpha$-flatoxin B-contaminated food $(4,5)$. HCC is hypothesized to represent a multi-stage process resulting from the accumulation of genetic changes $(6)$, including p53 $(7,8)$ and $\mathrm{Rb}$ inactivation (9) as well as TGF-ß (10) and Ras (11) activation.

HCC is frequently characterized by portal vein invasion and metastasis (1). One of the critical steps in carcinoma invasion and metastasis is the detachment of intercellular junctions of tumor cells, suggesting that cell surface molecules important for cell attachment might regulate this process in HCC. In this regard, the cadherins are transmembrane glycoproteins which mediate calcium-dependent cell-tocell adhesion, and play important roles in cell adhesion and cell signal transduction in a number of cell types $(12,13)$. Studies have shown that the classic cadherin molecules, $\mathrm{E}$-cadherin and $\mathrm{N}$-cadherin, are involved in the molecular pathogenesis of breast, lung, gastric and liver cancers (14-18). Loss of E-cadherin expression has been frequently reported in a diverse number of malignant tumors and the reintroduction of E-cadherin into highly invasive tumor cell lines results in suppression of both invasion and growth (19). In HCC, loss of E-cadherin expression correlates with hypermethylation and has been suggested to play an important role in HCC progression (20). Moreover, E-cadherin promoter methylation in $\mathrm{HCC}$ is correlated with microvascular invasion and recurrence $(21,22)$.

Unlike other cadherins, T-cadherin (for truncatedcadherin) is anchored to the membrane by a glycosylphos- 
phatidylinositol anchor and lacks the conventional transmembrane and cytoplasmic domains (23-25). Previous studies have shown that T-cadherin mediates calcium-dependent cell adhesion and colocalizes with small trimeric G-proteins and SRC family kinases in lipid rafts, where it may be involved in modulating signal transduction pathways (26-28). Our previous study demonstrated that $\mathrm{T}$-cadherin overexpression suppressed cell growth and motility by inducing a p21dependent G2 arrest in glioma cells (29). T-cadherin gene maps to human chromosome 16q24, and loss of T-cadherin expression has been reported in sporadic breast and lung cancers (30-32) pancreatic cancer tumors and cell lines (33), ovarian cancer (34), cutaneous squamous (35) and HCC (36). In the current study, we sought to determine the functional role of T-cadherin in HCC to define the relationship between $\mathrm{T}$-cadherin expression, promoter methylation and tumor behavior.

\section{Materials and methods}

Patients and specimens. Forty human HCC specimens and their corresponding adjacent normal liver tissues were collected from the surgical resection samples at Hepatic Surgical Center, Tongji Hospital, Huazhong University of Science and Technology from 2004 to 2005. All tumor specimens were pathologically diagnosed as HCC. Twenty specimens diagnosed as poorly-differentiated HCC and another 20 as moderately- or well-differentiated HCC were chosen for comparison. Eight out of 40 specimens were associated with intrahepatic portal vein invasion, whereas the other 32 specimens lacked intrahepatic portal vein invasion. Among the 40 patients, 32 patients were men and 8 women, aged from $30-72$ years, with an average of 49.4 years. All specimens were stored at $-80^{\circ} \mathrm{C}$ until analysis.

Immunohistochemical staining. Anti-T-cadherin (H126) polyclonal antibody was purchased from Santa Cruz Biotechnology (Santa Cruz, CA, USA). The sections from paraffinembedded specimens were prepared at 4-micrometer thickness. Antigen retrieval was performed in boiling citrate buffer for $15 \mathrm{~min}$. Peroxide blocking was preformed with $0.3 \%$ peroxide in absolute methanol. After the slides were incubated with anti-T-cadherin antibody at a 1:100 dilution at $4^{\circ} \mathrm{C}$ overnight and washed twice with PBS, they were then incubated with secondary antibody (Dako, USA) at room temperature for $30 \mathrm{~min}$. After washing, sections were incubated with immunoglobulins conjugated with horseradish peroxidase. Finally, the reaction was developed with 3,3'-diaminobenzidine. Tissue sections were counterstained with hematoxylin or methyl green. T-cadherin-expressing positive cells were defined only when T-cadherin staining was observed around the entire cell membranes. The percentage of positive cells were calculated by divided by the total number of hepatocytes in least 10 randomly chosen non-overlapping high-power (x400) fields for each case. $\mathrm{T}$-cadherin expression was graded on a scale from + to +++ . The percentage of the positive cells $\leq 25 \%$ were graded as '+', including those with absent staining. Tumors with $>25 \%$ but $<50 \%$ T-cadherin-immunoreactive cells were scored as ' ++ ', while tumors with $>50 \%$ were graded as ' +++ '.
DNA extraction and MSP. Briefly, extracting genomic DNA from tumor tissues, their corresponding liver tissues and the HepG2 cell line was performed by the digestion with proteinase K using a Genomic DNA Purification Kit (Gentra, USA). Following digestion, $1 \mu \mathrm{g}$ of genomic DNA was treated with the Chemicon $\mathrm{CpG}$ WIZ ${ }^{\mathrm{TM}}$ DNA Modification Kit (Chemicon, USA), which converts all unmethylated cytosines to uracil, leaving methylated cytosines unchanged (37). The modified DNA was diluted in TE buffer. Two sets of primers were used to amplify each region of interest: PCR amplification was performed with bisulfite-treated DNA as template using specific primer sequences for the methylated (i.e., unmodified by bisulfite treatment) and unmethylated (i.e., bisulfite modified to $\mathrm{UpG}$ ) forms of the gene. Aberrant promoter methylation of T-cadherin was determined by the method of MSP as reported previously (38). Primer sequences of T-cadherin for the unmethylated reaction were: T-cadherin UMS (sense), 5'-TTGTGGGGTTGTTTTTTGT-3', and Tcadherin UMAS (antisense), 5'-AACTTTTCATTCATA CACACA-3', which amplify a 242-base pair product. Primer sequences of $\mathrm{T}$-cadherin for the methylated reaction were: T-cadherin MS (sense), 5'-TCGCGGGGTTCGTTTTTC GC-3', and T-cadherin MAS (antisense), 5'-GACGTTTTCA TTCATACACGCG-3', which amplify a 243-base pair product (32). Results were confirmed by repeating bisulfite treatment and MSP assays for all samples.

$R T-P C R$. Total RNA was extracted from the HCC cell line HepG2, HCC tissues and their adjacent liver tissues with TRIzol (Invitrogen, USA) following the manufacturer's instructions. RT reaction was performed on $2 \mu \mathrm{g}$ of total RNA with the SuperScript II First-Strand Synthesis using an oligo(dT) primer system (Life Technologies, Inc.). Primer sequences and conditions for RT-PCR product were previously described (forward primer, 5'-TTCAGCAGAA AGTGTTCCATAT-3' and reverse primer, 5'-GTGCAT GGACGAACAGAGT-3') $(33,39)$. The housekeeping gene GAPDH was used as an internal control of the RT reaction (forward primer, 5'-AGAAGGCTGGGGCTCATTTG-3' and reverse primer, 5'-AGGGGCCATCCACAGTCTTC-3'). PCR was carried out for 32 cycles. The PCR amplification consisted of 1 cycle of $94^{\circ} \mathrm{C}$ for $5 \mathrm{~min} ; 30$ cycles of $94^{\circ} \mathrm{C}$ for $30 \mathrm{sec}, 50^{\circ} \mathrm{C}$ for $1 \mathrm{~min}$, and $72^{\circ} \mathrm{C}$ for $1 \mathrm{~min}$; and 1 cycle of $72^{\circ} \mathrm{C}$ for $10 \mathrm{~min}$. PCR products were analyzed on $2 \%$ agarose gels.

Western blotting. HepG2 cells and 5-aza-2-deoxycytidinetreated cells were lysed with sodium dodecyl sulfate (SDS) sample buffer (50 mM Tris- $\mathrm{HCl}, \mathrm{pH} 8.0,150 \mathrm{mM} \mathrm{NaCl}$, $0.02 \%$ sodium azide, $100 \mu \mathrm{g} / \mathrm{ml}$ phenylmethylsulfonyl fluoride, $50 \mathrm{mM}$ DTT, $1 \mu \mathrm{g} / \mathrm{ml}$ aprotinin and $1 \%$ Triton X-100). Liver tissues were homogenized using a homogenizer in RIPA lysis buffer (50 mM Tris-HCl, pH 8.0, 1\% NP40, 0.1\% SDS, $100 \mu \mathrm{g} / \mathrm{ml}$ phenylmethylsulfonyl fluoride, $0.5 \%$ sodium deoxycholate, $0.02 \%$ sodium azide, $1 \mu \mathrm{g} / \mathrm{ml}$ aprotinin and $150 \mathrm{Mm} \mathrm{NaCl}$ ) on ice. The supernatants were collected after centrifugation at $14,000 \mathrm{x} \mathrm{g}$ at $4^{\circ} \mathrm{C}$ for $10 \mathrm{~min}$. After protein concentration was determined, and whole-tissue lysates were mixed with an equal amount 5X SDS loading buffer (125 mM Tris-HCl, 4\% SDS, 20\% glycerol, 100 mM DTT 


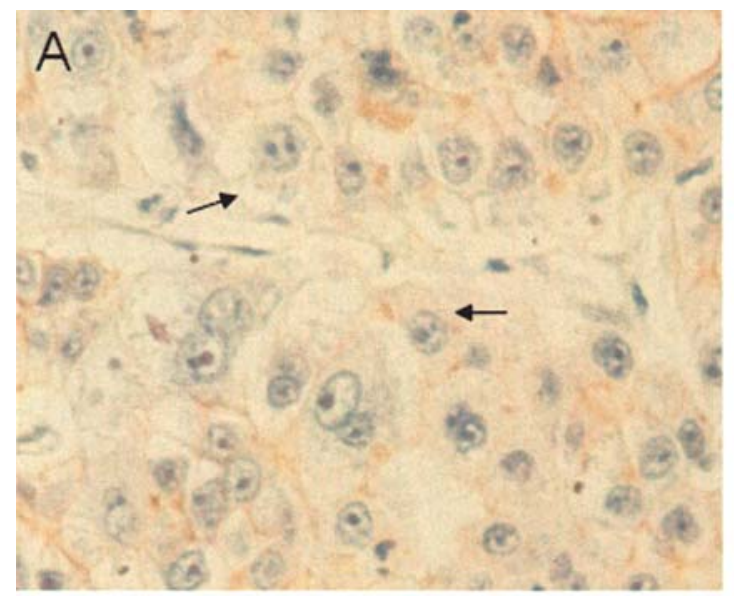

HCC tissues

C

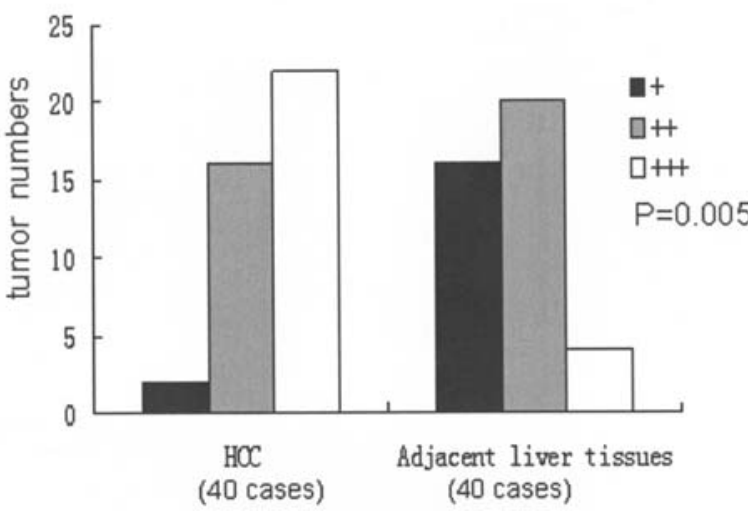

Figure 1. T-cadherin immunohistochemical staining shows reduced expression in HCC. (A) HCC tissue, arrow indicating cells with loss of T-cadherin expression. (B) Adjacent liver tissue, arrow showing cells with normal T-cadherin expression. (C) Semiquantitative analysis of T-cadherin expression in HCC tissues and their adjacent liver tissues. P-value corresponds to the comparison of T-cadherin expression in the HCC tissues and their adjacent liver tissues.

and $0.2 \%$ bromophenol blue), as described previously (40). Samples were heated at $100^{\circ} \mathrm{C}$ for $\sim 5-10$ min before loading and were separated on pre-casted $10 \%$ SDS-polyacrylamide gels (Fluka, USA). Proteins were electrotransferred onto nitrocellulose membranes (Invitrogen, USA) in transfer buffer. Non-specific binding to the membrane was blocked for $1 \mathrm{~h}$ at room temperature with 5\% non-fat milk in TBS buffer $(20 \mathrm{mM}$ Tris- $\mathrm{HCl}, 150 \mathrm{mM} \mathrm{NaCl}$ and $0.1 \%$ Tween20). Membranes were then incubated for overnight at $4^{\circ} \mathrm{C}$ with anti-T-cadherin antibody at a 1:1,000 dilution. The membranes were then incubated with horseradish peroxidaseconjugated secondary antibody at 1:5,000 dilution for $1 \mathrm{~h}$ at room temperature in $1 \%$ non-fat milk dissolved in TBS. Membranes were then washed with TBS buffer, and signals visualized using the enhanced chemiluminescence system (Pierce, USA).

Cell culture and cell growth. HepG2 liver cancer cells were cultured in Dulbecco's modified Eagle's medium (DMEM) supplemented with $10 \%$ fetal bovine serum and penicillinstreptomycin. To establish HepG2 cell growth curves, $10^{4}$

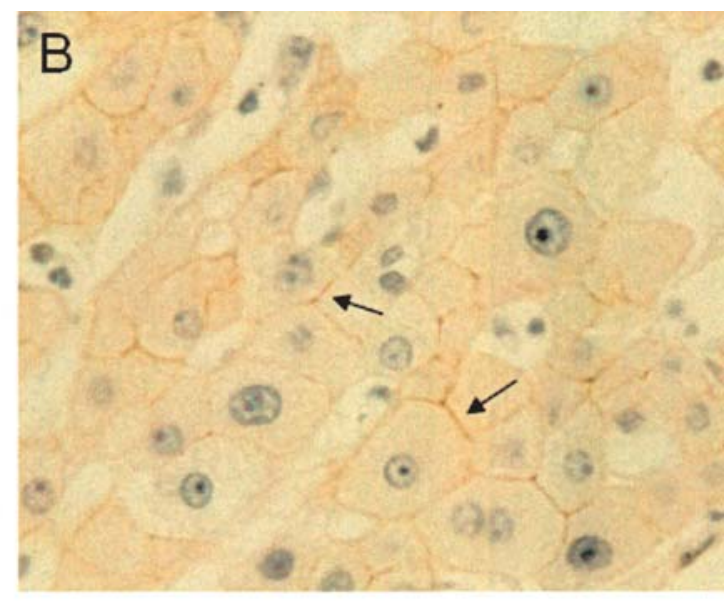

Adjacent liver tissues

cells were seeded on 18 6-cm diameter plates, and the medium was changed every three days. The plates were divided into two groups, each with 9 plates. One group was cultured with DMEM only, while the other group was cultured with DMEM plus the demethylation agent at $2 \mu \mathrm{M}$. Medium was changed every 2-3 days. Cell numbers were counted on days 3, 6 and 9 after seeding. The optimum concentration of demethylation agent was determined by culturing HepG2 cells with different concentrations of 5-aza2-deoxycytidine at $0,1,2,4,8,10,20$ and $40 \mu \mathrm{mol} / \mathrm{ml}$, respectively. Two $\mu \mathrm{M}$ was chosen as optimum concentration because it was the highest concentration at which the cells survived well and no drug-related cell death was observed in the culture. After cell counting, the cells of the two groups were subject to Western blot.

Data analysis. Statistical differences between groups were examined using Fisher's exact test. P-values of 0.05 were regarded as statistically significant.

\section{Results}

T-cadherin expression is down-regulated in HCC comparing to its corresponding liver tissue. By immunohistochemical staining, T-cadherin expression was located along the plasma cell membrane of hepatocytes in adjacent normal liver tissues (Fig. 1B), however, varying degrees of loss of T-cadherin expression were observed in HCC cells (Fig. 1A). There was a significantly difference in $\mathrm{T}$-cadherin expression between $\mathrm{HCC}$ and the corresponding liver tissue $(\mathrm{P}<0.01)$ (Fig. 1C).

Down-regulation of T-cadherin is closely associated with the malignant biological characteristics of HCC. To evaluate the correlation between the T-cadherin expression and the biological characteristics of HCC, T-cadherin expression was studied in 20 poorly-differentiated HCC and another 20 moderately- and well-differentiated HCC. The T-cadherin expression loss in the poorly-differentiated HCC were comparable to those in the moderately- and well-differentiated HCC (24.7\% vs. $35.1 \%)$, there was no significant difference in T-cadherin expression ( $\mathrm{P}=0.194)$ (Fig. 2A). However, in 8 specimens from the patients associated with intrahepatic 
A

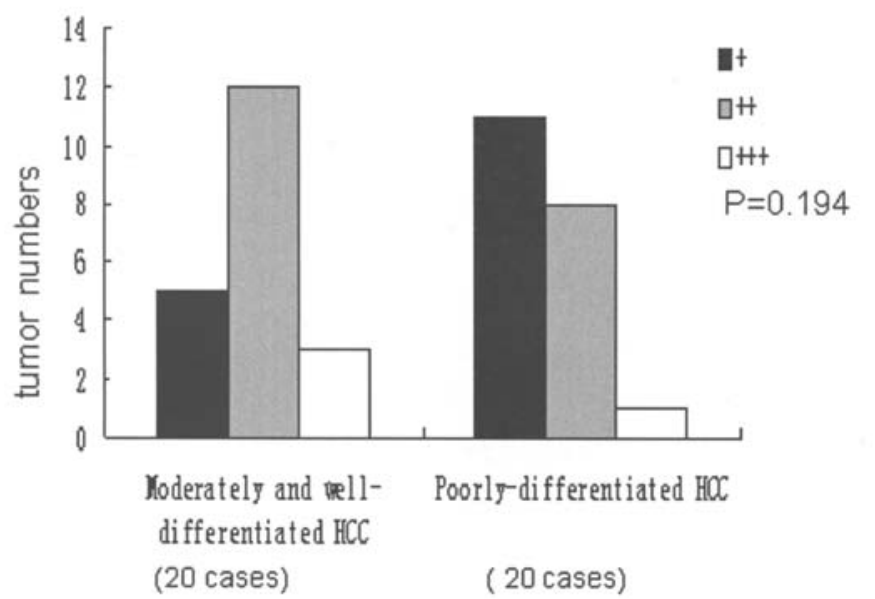

B

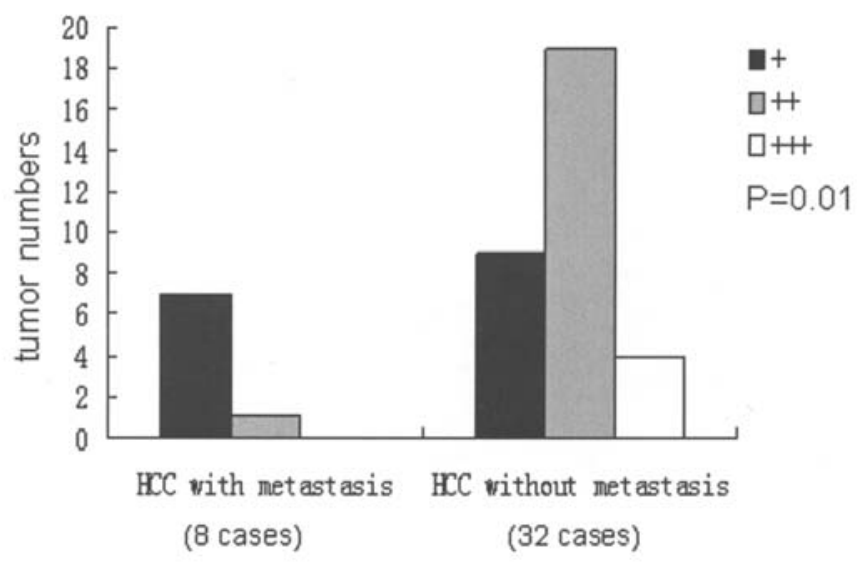

Figure 2. Semiquantitative analysis of T-cadherin expression in well- and moderately-differentiated HCC as well as poorly-differentiated HCC (A), and in HCC with and without portal vein metastasis (B). P-values correspond to the comparison of T-cadherin expression between the two groups.

A
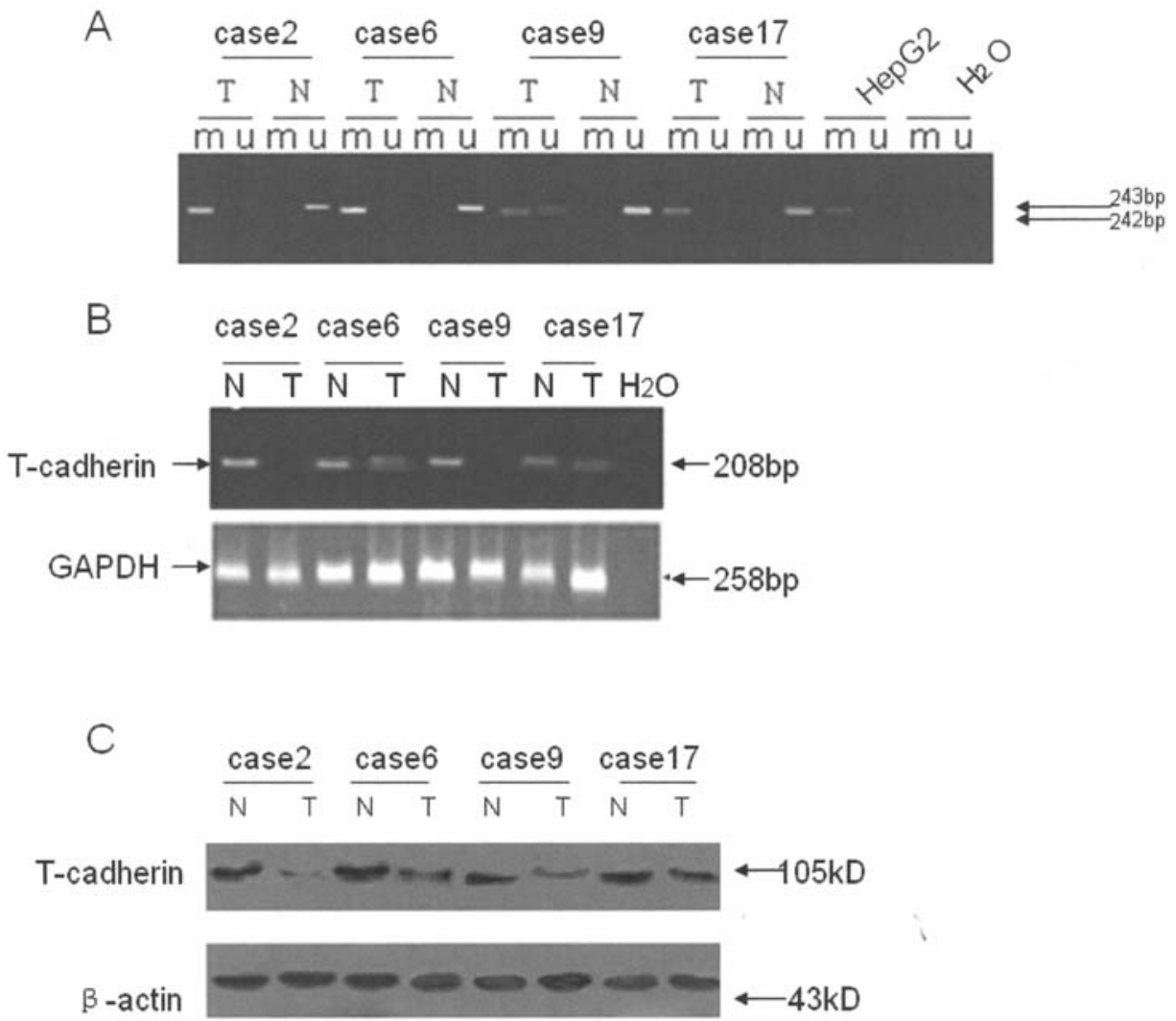

Figure 3. Correlation between T-cadherin promoter methylation and T-cadherin mRNA and protein expression. (A) Cases 2, 6, 9, 17 and HepG2 cells indicate $\mathrm{T}$-cadherin promoter methylation present in HCC tissues and HepG2 cells and absent in their adjacent liver tissues. ' $\mathrm{T}$ ' represents for HCC tissue, ' $\mathrm{N}$ ' for adjacent liver tissue; ' $m$ ' and ' $u$ ' represent for methylation and unmethylation status, respectively. (B) T-cadherin mRNA expression in cases $2,6,9$ and 17. T-cadherin mRNA expression in HCC samples was significantly decreased compared to their corresponding adjacent liver tissues. GAPDH was used as an internal control. (C) Western blotting shows the pattern of T-cadherin protein expression in HCC tumors from cases 2, 6, 9 and 17. 3 -actin was used as an internal control.

portal vein invasion, the T-cadherin expression was significantly lower than in the other 32 specimens from patients without intrahepatic portal vein invasion $(13.1 \%$ vs. $34.1 \%$, $\mathrm{P}=0.01$ ) (Fig. 2B).
Aberrant methylation contributes to the down-regulation of T-cadherin expression. To explore whether aberrant promoter methylation was responsible for the down-regulation of $\mathrm{T}$-cadherin expression in HCC tissues, T-cadherin promoter 
Table I. T-cadherin methylation status and clinicopathological findings in $20 \mathrm{HCC}$ patients.

\begin{tabular}{|c|c|c|c|c|c|c|c|c|c|c|}
\hline \multirow{2}{*}{$\begin{array}{l}\text { Case } \\
\text { no. }\end{array}$} & \multirow{2}{*}{ Age } & \multirow{2}{*}{ Sex } & \multirow{2}{*}{$\begin{array}{l}\text { Tumor } \\
\text { size }(\mathrm{cm})\end{array}$} & \multirow{2}{*}{$\begin{array}{l}\text { Portal vein } \\
\text { thrombus }\end{array}$} & \multirow{2}{*}{ Cirrhosis } & \multirow{2}{*}{ Differentiation } & \multirow{2}{*}{$\begin{array}{l}\mathrm{HBV} \text { or HCV } \\
\text { infection }\end{array}$} & \multirow{2}{*}{$\begin{array}{l}\text { Methylation } \\
\text { status }\end{array}$} & \multicolumn{2}{|c|}{$\mathrm{T}$-cadherin expression rate } \\
\hline & & & & & & & & & $\begin{array}{c}\mathrm{HCC} \\
\%\end{array}$ & $\begin{array}{c}\text { Adjacent liver } \\
\text { tissue } \%\end{array}$ \\
\hline 1 & 52 & $\mathrm{M}$ & $3.5 \times 3 \times 2.5$ & + & + & Poor & B & + & 25 & 54 \\
\hline 2 & 30 & $\mathrm{M}$ & $11 \times 6 \times 8$ & + & + & Mod & B & + & 0 & 37 \\
\hline 6 & 46 & $\mathrm{~F}$ & $13 \times 12 \times 9.5$ & + & + & Mod & B & + & 15 & 34 \\
\hline 9 & 48 & $\mathrm{M}$ & $4 \times 2.5 \times 2$ & - & + & Poor & B & + & 3 & 43 \\
\hline 10 & 48 & $\mathrm{~F}$ & $8 \times 7 \times 4.5$ & - & + & Well & - & + & 11 & 40 \\
\hline 15 & 59 & M & $5 \times 3 \times 3.5$ & + & + & Poor & B & + & 24 & 28 \\
\hline 17 & 53 & $\mathrm{M}$ & $10 \times 2 \times 8$ & - & + & Well & B & + & 9 & 45 \\
\hline 19 & 45 & $\mathrm{M}$ & $5 \times 4.5 \times 2$ & + & + & Poor & B & + & 10 & 28 \\
\hline 3 & 62 & $\mathrm{M}$ & $6 \times 6 \times 3.5$ & - & + & Poor & B & - & 30 & 54 \\
\hline 4 & 46 & $\mathrm{~F}$ & $3.2 \times 3 \times 2$ & - & + & Mod & B & - & 23 & 78 \\
\hline 5 & 53 & M & $7 \times 7 \times 3$ & + & + & Well & B & - & 31 & 79 \\
\hline 7 & 72 & M & $2.5 \times 1 \times 1.5$ & + & + & Well & B & - & 6 & 80 \\
\hline 8 & 35 & M & $10 \times 9 \times 8$ & - & + & Mod & B & - & 65 & 67 \\
\hline 11 & 46 & $\mathrm{M}$ & $4 \times 3 \times 2$ & - & + & Poor & B & - & 45 & 60 \\
\hline 12 & 47 & $\mathrm{M}$ & $4 \times 4 \times 2$ & - & + & Mod & $\mathrm{C}$ & - & 47 & 67 \\
\hline 13 & 50 & $\mathrm{~F}$ & $12 \times 10 \times 9$ & - & + & Mod & B & - & 34 & 65 \\
\hline 14 & 52 & $\mathrm{~F}$ & $8 \times 7.4 \times 6$ & - & + & Uncertain & B & - & 45 & 76 \\
\hline 16 & 53 & $\mathrm{M}$ & $10 \times 7.5 \times 8$ & - & + & Poor & B & - & 13 & 23 \\
\hline 18 & 54 & $\mathrm{M}$ & $3 \times 1.5 \times 1.5$ & + & + & Well & B & - & 34 & 60 \\
\hline 20 & 36 & $\mathrm{~F}$ & $14 \times 8 \times 9$ & - & + & Mod & B & - & 24 & 27 \\
\hline
\end{tabular}

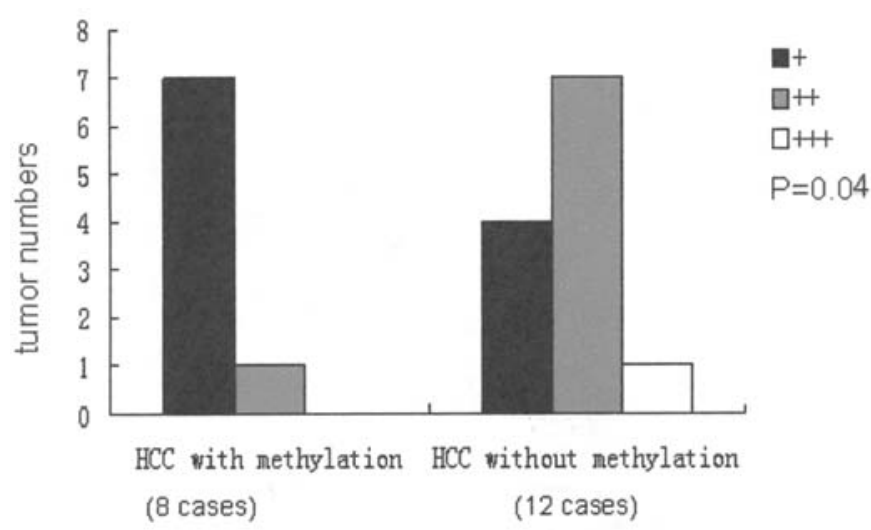

Figure 4. Semiquantitative analysis of T-cadherin protein expression in HCC with and without T-cadherin promoter methylation. P-value corresponds to the comparison of $\mathrm{T}$-cadherin positive expression in the two groups.

methylation status and the correlation between the promoter methylation status and T-cadherin expression were investigated in $20 \mathrm{HCC}$ specimens and their non-malignant counterparts. Promoter methylation was present in the $8 \mathrm{HCC}$ specimens and absent in all adjacent liver tissues (Fig. 3A). $\mathrm{T}$-cadherin methylation status and the clinicopathological characteristics of the $20 \mathrm{HCC}$ patients are shown in Table I. RT-PCR analysis confirmed that T-cadherin mRNA was significantly decreased or absent in all 8 HCC compared to their adjacent liver tissues (Fig. 3B). Furthermore, Western blot study demonstrated that $\mathrm{T}$-cadherin protein expression in 8 HCC samples with T-cadherin promoter methylation was significantly decreased compared to their adjacent liver tissues (Fig. 3C). Semiquantitative analysis of immunohistochemical staining indicated that the average $\mathrm{T}$-cadherin expression rate of $8 \mathrm{HCC}$ with the promoter methylation was significantly lower than that of the other $12 \mathrm{HCC}$ without promoter methylation ( $15.5 \%$ vs. $30.8 \%, \mathrm{P}=0.04)$ (Fig. 4), suggesting that the promoter methylation contributes to the regulation of T-cadherin expression in HCC. Furthermore, among the $8 \mathrm{HCC}$ with promoter methylation, $5 \mathrm{HCC}$ tumors $(5 / 8)$ were associated with portal vein tumor thrombus, indicating that the T-cadherin down-regulation by promoter methylation is associated with the development of portal vein tumor thrombus in HCC. However, among the $20 \mathrm{HCC}$, there were $17 \mathrm{HCC}$ with decreased T-cadherin mRNA and protein expression compared to their adjacent liver tissues, only 8 HCC were found with T-cadherin promoter methylation. These data demonstrate that the promoter methylation is involved in the down-regulation of T-cadherin in HCC, but that other mechanisms are involved in $\mathrm{T}$-cadherin regulation.

Demethylation results in increased $T$-cadherin expression and reduced HepG2 cell growth. We first showed that the human hepatoma cell line HepG2 exhibit T-cadherin promoter methylation (Fig. 3A). To study whether demethylation 

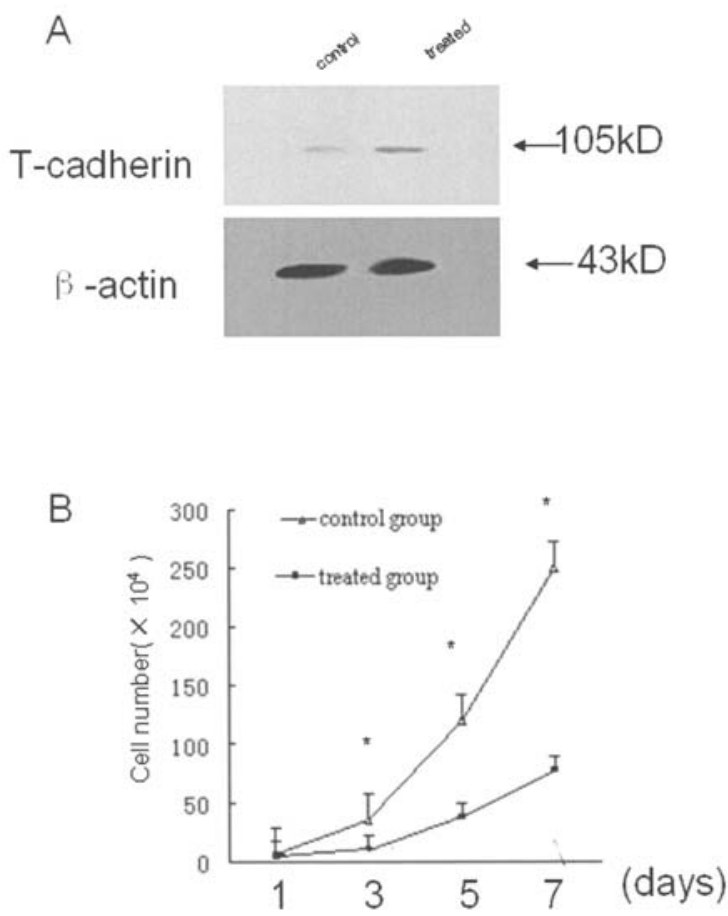

Figure 5. The demethylating agent 5-aza-2-deoxycytidine restores T-cadherin expression in HepG2 cells and suppresses cell growth. (A) Western blotting indicating a significant increase in T-cadherin expression after cells were treated with 5-aza-2-deoxycytidine at $2 \mu \mathrm{g} / \mathrm{ml}$ for 9 days, compared to cells without treatment. $\beta$-actin was used as an internal control. (B) Growth curves demonstrating reduced cell numbers in the 5-aza-2-deoxycytidine-treated group at different time points. Represents a significant statistic difference $(\mathrm{P}<0.05)$.

agents can restore T-cadherin expression in HepG2 cells, HepG2 cells were treated with $2 \mu \mathrm{M}$ of the demethylation agent 5-aza-2-deoxycytidine for 9 days, and the cell number determined on days 3, 6 and 9 after initial seeding. Western blot demonstrated that T-cadherin expression in the 5-aza2-deoxycytidine-treated cells was significantly increased compared to those untreated control cells (Fig. 5A). Moreover, $\mathrm{T}$-cadherin re-expression was associated with decreased cell growth following 5-aza-2-deoxycytidine treatment $(\mathrm{P}<0.05)$ (Fig. 5B).

\section{Discussion}

Studies of the underlying molecular mechanisms involved in HCC formation and progression provide tremendous opportunities to identify key molecules which may serve as additional targets for drug design in the treatment of liver tumors. Using molecular analysis, loss of heterozygosity has been found in several chromosomes in patients with HCC (20). Many of these chromosomal segments contain known tumor suppressor genes, such as p53 on 17p, p16 on 9p, and $\mathrm{RB}$ on $13 \mathrm{q}$. Mutations and overexpression of several oncogenes including ras, TGF- $\beta$ and c-myc have been identified in HCC patients (21-26). In light of previous studies implicating cadherin family members, such as E-cadherin and $\mathrm{N}$-cadherin, in the molecular pathogenesis of liver cancers $(17,20)$, we examined the expression and methylation of a novel member of the cadherin family, T-cadherin. T-cadherin is a truncated-cadherin that plays an important role not only in cell-cell adhesion but also in maintaining the normal cellular phenotype (23). Recent studies revealed that reexpression of T-cadherin in breast cancer cells (41) and glioma cell lines (29) inhibited the invasive potential and cell growth of tumor cells in vitro. T-cadherin maps to chromosome 16q24, and loss of chromosome 16q is one of most prevalent genetic alterations in HCC (42); however, $\mathrm{T}$-cadherin expression in $\mathrm{HCC}$ and the relationship between T-cadherin expression and HCC progression have not previously been investigated in human HCC.

In our study, we demonstrated that $\mathrm{T}$-cadherin expression was significantly decreased in HCC compared to their adjacent liver tissues. We also showed that decreased Tcadherin expression correlated with HCC portal vein invasion, suggesting that loss of $\mathrm{T}$-cadherin was also involved in the progression of HCC.

Aberrant methylation of T-cadherin promoter is one of the major mechanisms for the inactivation or downregulation of T-cadherin expression in a number of tumor types, including breast cancer $(43)$, lung cancer $(44,45)$ and colorectal cancer (46). Our studies indicated that in HCC, aberrant methylation of $\mathrm{T}$-cadherin promoter was present in 8 of $20 \mathrm{HCC}$, and these $8 \mathrm{HCC}$ tumors with promoter methylation had reduced T-cadherin mRNA and protein expression. Compared to the T-cadherin expression in other $12 \mathrm{HCC}$ tumors without methylation, T-cadherin expression in $8 \mathrm{HCC}$ tumors with $\mathrm{T}$-cadherin promoter methylation was significantly deceased $(\mathrm{P}<0.05)$, suggesting that promoter methylation contributes to the decreased $\mathrm{T}$ cadherin expression observed in HCC. Among the $8 \mathrm{HCC}$ tumors with the promoter methylation, 5 were associated with portal vein invasion; while in the other $12 \mathrm{HCC}$ tumors without promoter methylation, only three HCC were with portal vein invasion.

To determine whether T-cadherin promoter methylation contributes to the increased growth of HCC tumors, HepG2 cells were used to study whether treat-ment with a demethylation agent can restore T-cadherin expression. We found that the demethylation agent 5-aza-2-deoxycytidine was able to restore T-cadherin expression in HepG2 cells and reduce HepG2 cell growth.

Collectively, our data demonstrate that loss of T-cadherin expression resulting from the promoter methylation plays a role in the molecular pathogenesis of HCC, and suggest that $\mathrm{T}$-cadherin promoter methylation contributes to the reduction in T-cadherin expression in these tumors. Future studies on T-cadherin regulation may result in the development of novel targets for HCC therapies.

\section{Acknowledgements}

This work was supported by funding from the National Natural Science Foundation of China (No. 30471694) and the New Century Excellent Talent Foundation of China Ministry of Education (No. NCET-04-0701) to Dr Zhi-Yong Huang.

\section{References}

1. Chen XP and Huang ZY: Surgical treatment of hepatocellular carcinoma in China: surgical techniques, indications and outcomes. Langenbecks Arch Surg 390: 259-265, 2005. 
2. Chen XP, Wu ZD, Huang ZY and Qiu FZ: Use of hepatectomy and splenectomy to treat hepatocellular carcinoma with cirrhotic hypersplenism. Br J Surg 92: 334-339, 2005.

3. Chen XP, Qiu FZ, Wu ZD, Zhang ZW, Huang ZYand Chen YF: Long-term outcome of resection of large hepatocellular carcinoma. Br J Surg 93: 600-606, 2006.

4. Chen CJ, Yu MW and Liaw YF: Epidemiological characteristics and risk factors of hepatocellular carcinoma. J Gastroenterol Hepatol 12: S294-S308, 1997.

5. Yeh SH, Chen PJ, Lai MY and Chen DS: Allelic loss on chromosomes $4 \mathrm{q}$ and $16 \mathrm{q}$ in hepatocellular carcinoma: association with elevated $\alpha$-fetoprotein production. Gastroenterology 110 : 184-192, 1996

6. Piao Z, Kim H, Jeon BK, Lee WJ and Park C: Relationship between loss of heterozygosity of tumor suppressor genes and histologic differentiation in hepatocellular carcinoma. Cancer 80: 865-872, 1997

7. Dewantoro O, Gani RA and Akbar N: Hepatocarsinogenesis in viral hepatitis B infection: the Role of $\mathrm{HBx}$ and p53. Acta Med Indones 38: 154-159, 2006.

8. Feitelson MA, Pan J and Lian Z: Early molecular and genetic determinants of primary liver malignancy. Surg Clin North Am 84: 339-354, 2004

9. Suriawinata A and $\mathrm{Xu} \mathrm{R}$ : An update on the molecular genetics of hepatocellular carcinoma. Semin Liver Dis 24: 77-88, 2004.

10. Ikeguchi M, Iwamoto A, Taniguchi K, Katano K and Hirooka Y: The gene expression level of transforming growth factor-beta (TGF-beta) as a biological prognostic marker of hepatocellular carcinoma. J Exp Clin Cancer Res 24: 415-421, 2005.

11. Calvisi DF, Ladu S, Gorden A, et al: Ubiquitous activation of Ras and Jak/Stat pathways in human HCC. Gastroenterology 130: 1117-1128, 2006.

12. Elangbam CS, Qualls CW Jr and Dahlgren RR: Cell adhesion molecules - update. Vet Pathol 34: 61-73, 1997.

13. Albelda SM: Role of integrin and other cell adhesion molecules in tumor progression and metastasis. Lab Invest 68: 4-17, 1993.

14. Berx G and F Van Roy F: The E-cadherin/catenin complex: an important gatekeeper in breast cancer tumorigenesis and malignant progression. Breast Cancer Res 3: 289-293, 2001.

15. Bremnes RM, Veve R, Gabrielson E, et al: High-throughput tissue microarray analysis used to evaluate biology and prognostic significance of the E-cadherin pathway in non-smallcell lung cancer. J Clin Oncol 20: 2417-2428, 2002.

16. Handschuh $\mathrm{G}$, Candidus S, Luber B, et al: Tumour-associated E-cadherin mutations alter cellular morphology, decrease cellular adhesion and increase cellular motility. Oncogene 18: 4301-4312, 1999

17. Levenberg S, Yarden A, Kam Z and Geiger B: p27 is involved in $\mathrm{N}$-cadherin-mediated contact inhibition of cell growth and S-phase entry. Oncogene 18: 869-876, 1999.

18. Nieman MT, Prudoff RS, Johnson KR and Wheelock MJ: $\mathrm{N}$-cadherin promotes motility in human breast cancer cells regardless of their E-cadherin expression. J Cell Biol 147: 631-644, 1999.

19. Vleminckx K, Vakaet L, Mareel M, Fiers W and van Roy F: Genetic manipulation of E-cadherin expression by epithelial tumor cells reveals an invasion suppressor role. Cell 66: 107-119, 1991

20. Yang B, Guo M, Herman JG and Clark DP: Aberrant promoter methylation profiles of tumor suppressor genes in hepatocellular carcinoma. Am J Pathol 163: 1101-1107, 2003.

21. Kwon GY, Yoo BC, Koh KC, Cho JW, Park WS and Park CK: Promoter methylation of E-cadherin in hepatocellular carcinomas and dysplastic nodules. J Korean Med Sci 20: 242-247, 2005.

22. Lee S, Lee HJ, Kim JH, Lee HS, Jang JJ and Kang GH: Aberrant $\mathrm{CpG}$ island hypermethylation along multistep hepatocarcinogenesis. Am J Pathol 163: 1371-1378, 2003

23. Angst BD, Marcozzi C and Magee AI: The cadherin superfamily: diversity in form and function. J Cell Sci 114: 629-641, 2001.

24. Ranscht B and Dours-Zimmermann MT: T-cadherin, a novel cadherin cell adhesion molecule in the nervous system lacks the conserved cytoplasmic region. Neuron 7: 391-402, 1991.

25. Vestal DJ and Ranscht B: Glycosyl phosphatidylinositolanchored T-cadherin mediates calcium-dependent, homophilic cell adhesion. J Cell Biol 119: 451-461, 1992.

26. Doyle DD, Goings GE, Upshaw-Earley J, Page E, Ranscht B and Palfrey HC: T-cadherin is a major glycophosphoinositolanchored protein associated with non-caveolar detergentinsoluble domains of the cardiac sarcolemma. J Biol Chem 273 : 6937-6943, 1998
27. Kinch MS, Petch L, Zhong C and Burridge K: E-cadherin engagement stimulates tyrosine phosphorylation. Cell Adhes Commun 4: 425-437, 1997

28. Philippova MP, Bochkov VN, Stambolsky DV, Tkachuk VA and Resink TJ: T-cadherin and signal-transducing molecules co-localize in caveolin-rich membrane domains of vascular smooth muscle cells. FEBS Lett 429: 207-210, 1998.

29. Huang ZY, Wu Y, Hedrick $N$ and Gutmann DH: T-Cadherinmediated cell growth regulation involves $\mathrm{G} 2$ phase arrest and requires p21CIP1/WAF1 expression. Mol Cell Biol 23: 566-578, 2003

30. Lee SW: H-cadherin, a novel cadherin with growth inhibitory functions and diminished expression in human breast cancer Nat Med 2: 776-782, 1996.

31. Toyooka KO, Toyooka S, Virmani AK, et al: Loss of expression and aberrant methylation of the CDH13 (H-cadherin) gene in breast and lung carcinomas. Cancer Res 61: 4556-4560, 2001

32. Zhong Y, Delgado Y, Gomez J, Lee SW and Perez-Soler R Loss of H-cadherin protein expression in human non-small cell lung cancer is associated with tumorigenicity. Clin Cancer Res 7: 1683-1687, 2001.

33. Sakai M, Hibi K, Koshikawa K, Inoue S, Takeda S, Kaneko T and Nakao A: Frequent promoter methylation and gene silencing of CDH13 in pancreatic cancer. Cancer Sci 95: 588-591, 2004

34. Kawakami M, Staub J, Cliby W, Hartmann L, Smith DI and Shridhar V: Involvement of H-cadherin (CDH13) on $16 \mathrm{q}$ in the region of frequent deletion in ovarian cancer. Int J Oncol 15: 715-720, 1999

35. Takeuchi T, Liang SB, Matsuyoshi N, Zhou S, Miyachi Y, Sonobe $\mathrm{H}$ and Ohtsuki Y: Loss of T-cadherin (CDH13, Hcadherin) expression in cutaneous squamous cell carcinoma. Lab Invest 82: 1023-1029, 2002.

36. Riou P, Saffroy R, Comoy J, et al: Investigation in liver tissues and cell lines of the transcription of 13 genes mapping to the $16 q 24$ region that are frequently deleted in hepatocellular carcinoma. Clin Cancer Res 8: 3178-3186, 2002.

37. Wang RY, Gehrke CW and Ehrlich M: Comparison of bisulfite modification of 5-methyldeoxycytidine and deoxycytidine residues. Nucleic Acids Res 8: 4777-4790, 1980.

38. Herman JG, Graff JR, Myohanen S, Nelkin BD and Baylin SB Methylation-specific PCR: a novel PCR assay for methylation status of CpG islands. Proc Natl Acad Sci USA 93: 9821-9826, 1996

39. Sato M, Mori Y, Sakurada A, Fujimura S and Horii A: The $\mathrm{H}$-cadherin (CDH13) gene is inactivated in human lung cancer. Hum Genet 103: 96-101, 1998

40. Gutmann DH, Huang ZY, Hedrick NM, Ding H, Guha A and Watson MA: Mouse glioma gene expression profiling identifies novel human glioma-associated genes. Ann Neurol 51: 393-405, 2002.

41. Miki Y, Katagiri T and Nakamura Y: Infrequent mutation of the H-cadherin gene on chromosome $16 q 24$ in human breast cancers. Jpn J Cancer Res 88: 701-704, 1997.

42. Marchio A, Meddeb M, Pineau P, Danglot G, Tiollais P Bernheim A and Dejean A: Recurrent chromosomal abnormalities in hepatocellular carcinoma detected by comparative genomic hybridization. Genes Chromosomes Cancer 18: 59-65, 1997.

43. Fiegl H, Millinger S, Goebel G, et al: Breast cancer DNA methylation profiles in cancer cells and tumor stroma: association with HER-2/neu status in primary breast cancer. Cancer Res 66: 29-33, 2006

44. Ulivi P, Zoli W, Calistri D, et al: p16INK4A and CDH13 hypermethylation in tumor and serum of non-small cell lung cancer patients. J Cell Physiol 206: 611-615, 2006.

45. Kim JS, Han J, Shim YM, Park J and Kim DH: Aberrant methylation of H-cadherin (CDH13) promoter is associated with tumor progression in primary non-small cell lung carcinoma. Cancer 104: 1825-1833, 2005

46. Hibi K, Kodera Y, Ito K, Akiyama S and Nakao A: Aberran methylation of HLTF, SOCS-1, and CDH13 genes is shown in colorectal cancers without lymph node metastasis. Dis Colon Rectum 48: 1282-1286, 2005. 